WHITE FRAGILITY

This paper has been accepted for publication at American Psychologist.

(C) 2021, American Psychological Association.

This paper is not the copy of record and may not exactly replicate the final, authoritative version of the article. Please do not copy or cite without authors' permission. The final article will be available, upon publication, via its DOI: $10.1037 / \mathbf{a m p 0 0 0 0 9 6 8}$

\title{
White Fragility:
}

\section{An Emotion Regulation Perspective}

\author{
Brett Q. Ford \\ Dept. of Psychology \\ University of Toronto
}

\author{
Dorainne J. Green \\ Dept. of Psychological \& Brain Sciences \\ Indiana University \\ James J. Gross \\ Dept. of Psychology \\ Stanford University
}

\begin{abstract}
Author Note
All authors contributed to the conceptualization and writing of this manuscript. We have no conflicts of interest to disclose. Correspondence regarding this article should be addressed to: Brett Ford, University of Toronto, Department of Psychology, 1265 Military Trail, Toronto, ON, M1C1A4. Email: Brett.Ford@utoronto.ca.

The authors would like to thank members of the Stanford Psychophysiology Laboratory, Ivuoma Onyeador, and Régine Debrosse for their helpful feedback.

The authors describe their own positionality at the time when this paper was drafted: one author self-identified as a White American woman, another self-identified as a White American man, and another self-identified as a Black Caribbean American woman.
\end{abstract}




\begin{abstract}
To address anti-Black racism, systemic change across many domains in American life will be necessary. There are many barriers to change, however, and progress requires identifying these barriers and developing tools to overcome them. Given that White individuals disproportionately occupy 'gatekeeping' positions of power, one key barrier to systemic change is rooted in White individuals' emotional (and emotion-regulatory) responses when considering their own role in racism (e.g., involvement in racist systems, biased actions). White people often experience such moments as a jeopardy to their valued goals and are consequently highly motivated to reduce the negative emotions they feel by denying or avoiding the issue - a multi-faceted response known as a White fragility response. When White individuals enact a White fragility response, they can further damage the well-being of Black members of their community and weaken their own motivation for systemic change. Given its stark costs, it is critical to understand White fragility responses. In this article, we argue that White fragility can be usefully viewed through the lens of emotion and emotion regulation theory. In particular, we describe the emotion and emotion regulation responses that characterize White fragility, summarize the wide-ranging consequences of White fragility responses, highlight more sustainable ways forward, and end by considering a broader fragility framework that acknowledges multiple dimensions of power. Although emotion regulation lies at the heart of White fragility, emotion regulation is also a tool that can be leveraged for greater justice.
\end{abstract}

Keywords: White fragility, anti-Blackness, Racism, Emotion, Emotion regulation

Public Significance Statement: To combat deep-seated racism, we must use all of the tools that psychological science has to offer. We propose that emotion regulation theory can help both to explain why White individuals are often unwilling to consider their own role in racism and to identify several promising ways forward, towards a more just future. 


\section{White Fragility: An Emotion Regulation Perspective}

The killing of George Floyd on May 25, 2020 represents a devastating milestone in the long history of racial injustice in the United States. During the unprecedented wave of protests that followed the killing of yet another Black man by a White police officer, people demanded that the injustice be addressed. As people of color have become more vocal about inequality, White myths about race and inequality are being challenged (Kraus et al., 2019). This is uncomfortable for many White individuals, as it is the first time they have had to contend with their race and its privileges. White individuals are being called upon to recognize their role in the status quo, and to actively work towards change across many domains in American life. While much important activism is being led by the Black community, White participation is also crucial, in no small part because Whites disproportionately occupy 'gatekeeping' high-power positions in society (Boykin et al., 2020). There are many barriers to fully engaging White individuals in this effort, however, and progress requires identifying these barriers and developing tools to overcome them.

We propose that one key barrier to systemic change is rooted in White individuals' emotional responses to considering their own role in racism (e.g., acts of bias, involvement in racist systems). White people often appraise such moments as jeopardizing their fundamental goal to be 'good' (e.g., to not harm others, to have earned one's successes: Bergsieker et al., 2010, Knowles et al., 2014). Such appraisals typically evoke a negative emotional reaction (e.g., anger, anxiety, guilt, sadness) and very often, these negative emotions evoke attempts to regulate that emotional reaction (e.g., avoidance, rationalization, silence). This constellation of emotional and regulatory responses has been referred to as 'White fragility' (DiAngelo, 2011, 2018). The term 'White fragility' may suggest a unitary phenomenon, but we argue this is an umbrella term for a variety of responses which are engendered by various elicitors and embodied via many different emotions and regulation 
strategies. Whatever shape it takes, a White fragility response has consequences. The emotional response can be harmful to the people receiving or witnessing it, therefore risking the well-being of Black community members (e.g., coworkers, neighbors). Or, the common ways of regulating this emotional response can provide momentary emotional relief, but can further demotivate White individuals from addressing underlying systemic problems (Knowles et al., 2014).

Given its stark downsides, it is crucial to understand and disrupt White fragility responses. Here, we propose that emotion and emotion regulation theory (Gross, 2015) can be leveraged to gain insight into White fragility and develop alternative responses more likely to promote justice. In our analysis, we bridge disciplines within psychology - integrating emotion and emotion regulation theory with intergroup relations research - as well as across other fields, including philosophy and sociology. We aim to build a conceptual framework that can inspire theoretically-grounded empirical work to thoroughly examine White fragility - a concept that has significant resonance within the broader public, but has received little empirical research. We intend for this framework to bring conceptual clarity to complex ideas that have been previously discussed in more general terms (e.g., DiAngelo, 2018). As such, we draw from closely related research as much as possible (e.g., emotional responses in intergroup settings) and also draw from more distal but highly conceptuallyrelevant research (e.g., emotional responding in general), noting when the evidence is more indirect.

Below, we first describe a conceptual framework for the emotional responses that characterize White fragility. Second, we articulate a conceptual framework for the emotionregulation strategies that also characterize White fragility. Third, we summarize the empirical evidence of the wide-ranging consequences of these White fragility responses, including personal, interpersonal, and societal outcomes. Fourth, we highlight several ways forward, including practical approaches to dealing with one's emotions that do not undermine Black community members or 
systemic change. Finally, we show how our analysis suggests a broader framework for examining White fragility in the context of other possible forms of fragility - a framework that acknowledges the complex multi-dimensional social space in which we are embedded. By understanding the role of fragility in maintaining various intersecting systemic inequalities, we can make progress in dismantling these inequalities as well.

\section{White Fragility: The Emotional Response}

White fragility ${ }^{1}$ often involves a potent negative emotional response. Although this response is often discussed as 'distress' or 'discomfort' (DiAngelo, 2018), we note that the response can be diverse, including anger, anxiety, guilt, sadness, and others. Given that not all instances of these emotions are White fragility responses, we identify boundary conditions in our discussion below. The generation of a White fragility response - like any other emotional response - unfolds over time and involves several core elements: The emotion begins with a situation, which can be external (in the world) or internal (in one's mind). A person attends to the situation and then appraises the situation in reference to their goals (Moors et al., 2013). This evaluation sets the stage for an emotional response that prepares the person to act in the situation (Barrett, 2012). Here, we discuss each of these elements, drawing upon long-standing theoretical models of emotional responding (Gross, 2015; Lazarus \& Folkman, 1987; Scherer, 2001) and proposing how these elements likely unfold within a fragility response (Figure 1). Although we focus on the psychological processes involved in generating a White fragility response, we also note that these processes take place in a social context that prioritizes Whiteness on a large scale and can further shape fragility responses.

\footnotetext{
${ }^{1}$ We focus our discussion on White people given the historical context of Whiteness and the privilege associated with it. Although people of other racial/ethnic backgrounds may also experience negative emotional responses (and regulate those responses) in contexts where their racial identity is salient, such responses can only constitute White fragility when experienced in the context of Whiteness and the privileges afforded to White people (e.g., whereby White people's emotional responses and/or regulatory responses have a disproportionately large influence on the Black community).
} 


\section{Figure 1}

Overview of how the White fragility emotional response unfolds (lighter gray), and how each element of this response can be targeted by the White fragility regulatory response that White individuals - upon identifying the need to regulate - select and implement (darker gray). This model derives from the process model of emotion regulation (Gross, 2015).

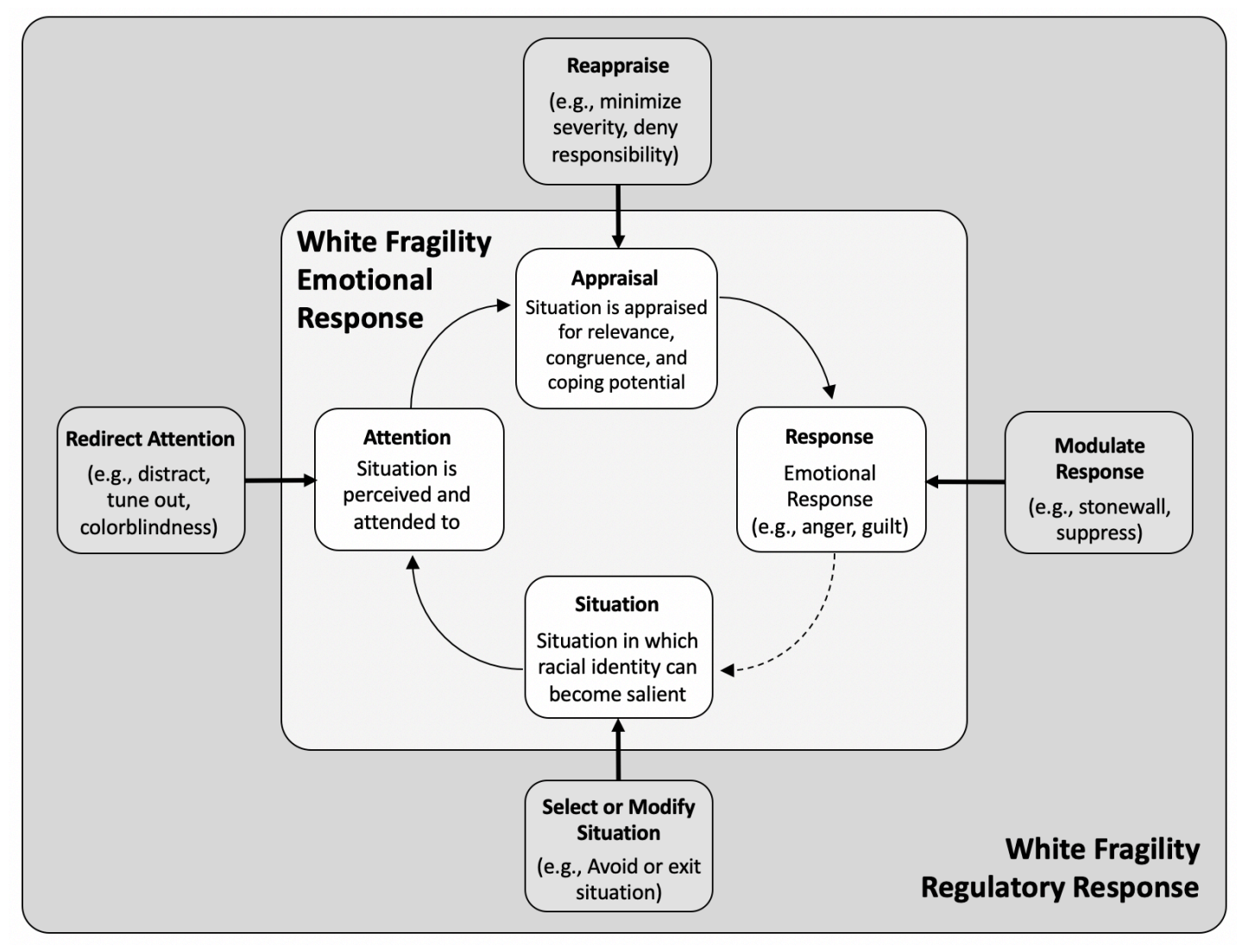

\section{Situation}

White fragility responses can be evoked in many different situations that provide the opportunity for someone's racial identity as a White person to become salient to them (DiAngelo, 2018). We propose this may occur when a White person considers their own racially biased thoughts and behaviors (Perry et al., 2015), or even when they are merely asked to consider their race (Helms, 1997) or the implications of being White (Knowles et al., 2014; Phillips \& Lowery, 2018). As such, White fragility can occur within interracial interpersonal interactions (e.g.,

Trawalter et al., 2009) or outside of such interactions (e.g., watching the news, conversations with 
other White people), and can occur in situations that personally involve the individual or are only relevant to one's group (setting the stage for a group-based emotion; Goldenberg et al., 2016; Smith \& Mackie, 2008). For this reason, there are countless opportunities for fragility, depending on how the attention and appraisal elements unfold.

\section{Attention}

Upon exposure to the types of situations outlined above, the White person may then perceive and attend to the situation. This attention need not be full or deliberate. Indeed, part of White people's privilege (i.e., advantages they have merely due to being White; McIntosh, 2020) often involves not spontaneously considering race (Helms, 1997). However, we also note that race can still become salient through other means (e.g., when prompted by the media, friends, or coworkers), which can be quite frequent. Importantly, given that White people do not often consider their own race or racial privilege, when it does become salient, it may serve as a particularly potent stimulus.

\section{Appraisal}

Upon attending to a situation in which their racial identity has become salient to them, the White person appraises the situation in reference to their own goals. We propose that the fundamental, superordinate goal to be 'good' (i.e., to view themselves - or be viewed by others positively) is most relevant to generating White fragility. Integrating across multiple psychological traditions centered on how people make sense of the world in general (Lazarus \& Folkman, 1987; Scherer, 2001), we propose that three core appraisals - when combined - are sufficient for generating a White fragility emotional response: goal relevance, goal congruence, and low coping potential. Specifically, we propose that White fragility emotional responses arise when situations where a White person's race is salient to them are appraised as (a) relevant to their goal to be viewed positively, (b) incongruent with their goal to be viewed positively (e.g., someone thinks they 
said something racist), and yet (c) they do not think they have the resources to successfully handle the situation (e.g., they don't think they can manage the situation to avoid being viewed as racist). This combination of appraisals can be summarized as one's core goal to be 'good' as being in jeopardy (i.e., the relevant situation is incongruent with the goal and the person also does not think they can rectify the situation to protect the goal). While this combination is sufficient to generate a White fragility emotional response, the precise nature of that emotion hinges on more specific appraisals (e.g., an appraisal of personal culpability may lead to guilt or sadness, whereas an appraisal of another's culpability may lead to anger or disgust; Siemer et al., 2007).

This approach leverages existing models of emotional responding (e.g., Scherer, 2001; Lazarus \& Folkman, 1987) to provide a more fine-grained analysis that can account for the emotions that other theorists have noted are central to White fragility (DiAngelo, 2018; Liebow \& Glazer, 2019). In so doing, we are able to more systematically articulate the necessary features that underlie White fragility emotional responses and define useful boundary conditions that distinguish fragility from other experiences: First, White fragility responses are not possible for people who are not White. This may go without saying, but it is an important distinguishing feature from other constructs (e.g., interracial anxiety, which people of any race can experience; Plant \& Devine, 2003). Second, White fragility emotional responses are improbable if their own identity as a White person has not become salient to them (e.g., a White person is saddened when learning about the U.S.'s history of anti-Black racism in the U.S., but their own White identity is not salient). Third, White fragility responses are improbable in a situation where White identity is salient but is not appraised as relevant to and incongruent with a goal to be 'good' (e.g., a White person is outraged at the societal injustice of anti-Black racism, but this situation is not appraised as bearing on the individual's 'goodness'). Finally, White fragility responses can be unlikely in a situation where 
White identity is salient but is appraised as a situation where they can cope (e.g., a White person learns that they harmed a non-White co-worker but is confident that they can make amends), but we also note that low coping potential is not a necessary appraisal for White fragility: one can appraise the situation as having high coping potential and still demonstrate White fragility if this appraisal leads the person to cope with the situation by using emotion regulation characterized by White fragility, as discussed below in the section on White fragility regulatory responses (e.g., avoiding the co-worker for the foreseeable future; bullying the co-worker to make them back down).

We propose that many different situations in which a White person's racial identity is salient to them can evoke this pattern of appraisals (i.e., that their goal to be 'good' is in jeopardy). Being 'good' can mean different things at different times, and to different people. For example, the goal of being good by not harming other people can be jeopardized when people consider racist things they have said or done, or when they consider their silence or inaction in the face of others' racism (Nelson et al., 2011). Or the goal of being good and therefore being viewed positively by others can be jeopardized when people are perceived as prejudiced themselves (Frantz et al., 2004; Phillips \& Lowery, 2018; Plant \& Devine, 2003; Srivastava, 2005), including one's implicit bias (Plant \& Devine, 2003; Vitriol \& Moskowitz, 2021), or when concerned about confirming negative stereotypes about White people (i.e., social identity threat; Branscombe et al., 1999). These particular contexts may be particularly powerful drivers of White fragility for people who are especially concerned about being perceived negatively or as prejudiced (Bergsieker et al., 2010).

Additionally, the goal of being good and therefore having one's group also be viewed positively can be jeopardized when people are asked to consider their group's oppressive history of White supremacy (i.e., a history of structural advantages over other ethnic groups; Gillborn, 2005). Or, the goal of being good and therefore having earned one's successes (i.e., meritocracy) can be 
jeopardized when people are asked to consider their own unearned advantages (Knowles et al., 2014). These particular contexts may be more powerful drivers of White fragility for people who are relatively unconcerned about appearing prejudiced (e.g., who align more explicitly with racist values) and/or who are more likely to support systems in which they are embedded (e.g., system justification; Jost \& Hunyady, 2005).

These few examples are by no means an exhaustive list. Indeed, we propose that nearly all White people are susceptible to moments of fragility given the variety of situations that can elicit fragility (including situations that are relevant to people who are concerned about racism as well as people who endorse racism). People may still differ in the relative frequency or intensity of these experiences, however, and it remains an important empirical question how common White fragility responses are in daily life and which individual differences predict those responses.

\section{Response}

Upon appraising the situation as one where their fundamental goal of being 'good' is in jeopardy, White people experience unpleasant emotions (e.g., guilt, sadness, frustration, anger, anxiety) - the White fragility emotional response. Theorists of White fragility propose these feelings are often intense (DiAngelo, 2018), but it is also possible for these feelings to be mild. The precise emotion will also vary depending on the particular features of the person's (perceived) situation and subgoals (Lazarus, 1991). The experience may also be mixed, given that the current situation may be relevant to (and incongruent with) multiple subgoals, spurring multiple relevant appraisals and a complex emotional response (e.g., sadness when considering the realities of racism and also guilt when considering one's role in those realities). For example, during a college classroom discussion of White privilege (i.e., considering various advantages White people have merely for being White; McIntosh, 2020), approximately $75 \%$ of White students reported a wide range of negative emotions 
(e.g., shocked, upset, guilty, uncomfortable, resentment, etc.; Boatright-Horowitz et al., 2012). This descriptive research usefully highlights the breadth of the scope of possible fragility emotional responses, although we also note that these would only qualify as a White fragility emotional responses if they matched the pattern of emotion-generating appraisals outlined above.

As the emotional response unfolds across time, we propose that an initial response may even become the object of a secondary meta-emotional response, which may further exacerbate the emotional episode (e.g., feeling guilty, and then feeling angry about feeling guilty). Often cooccurring with these emotional experiences are emotional expressions, which can take many forms based on one's internal experiences and socio-cultural norms for emotion expression (e.g., crying, which takes on heightened meaning in an inter-racial context; cf. Accapadi, 2007). Such emotional experiences and expressions can, in turn, have an influence on the dynamically-unfolding situation itself, as depicted in Figure 1 (e.g., as an anger expression impacts one's interaction partner), but this influence can be attenuated by other factors (e.g., if the individual regulates the emotion).

\section{Interim Summary}

In sum, the emotional response element of White fragility can be elicited in many different situations in which a White person's racial identity is salient that and their fundamental goal of being 'good' is jeopardized, resulting in negative emotions. These emotions, in turn, will often become the target of regulatory attempts whereby White people strive to feel better. This brings us to the issue of emotion regulation - another crucial element of the White fragility response.

\section{White Fragility: The Regulatory Response}

Consistent with other theorizing (DiAngelo, 2018; Langrehr et al., 2021; Liebow \& Glazer, 2019), we propose that White fragility responses often involve not only a negative emotional reaction (e.g., anger, anxiety, guilt, sadness), but also attempts to regulate these emotions (see 
Figure 1). We note that emotion generation and regulation often blend together in daily life, but we maintain a distinction between the two as conceptually and practically useful. Building upon the process model of emotion regulation (Gross, 2015), we propose that the regulation of an emotion in the context of fragility - as in any context - unfolds over time and involves several core elements: The person identifies the need to regulate the emotion(s), chooses a strategy they think will achieve their desired emotion, and then implements their strategy (Gross, 2015). Throughout this process, the person monitors their progress to determine whether the desired emotion has been achieved (e.g., they feel better) or if additional regulation is needed. This model can organize the many ways in which people regulate the emotions that arise during a White fragility response, providing more conceptual clarity to guide future empirical work examining the key nuances of these processes.

\section{Identifying the Need to Regulate}

The first step in the regulation process is identifying whether a particular emotion needs to be regulated. It is important to note that people do not always strive to reduce negative emotions like anger or guilt. Prior research from outside race-related contexts indicates that people choose to experience negative emotions for a variety of reasons: the emotions feel familiar or authentic (Ford $\&$ Tamir, 2014), the emotions help the person connect to their group (Goldenberg et al., 2016), or the emotions help the person achieve other valued goals (Tamir, 2016).

Although there may be several reasons for someone to choose not to reduce their emotional response, White Americans often tend to want to reduce distress after a negative event (Miyamoto et al., 2014), and perhaps especially in race-centered contexts (Bergsieker et al., 2010). The person may want to reduce negative emotions for hedonic reasons (e.g., to feel better), but also for instrumental or performative reasons (e.g., to save face; cf. Tamir, 2016). Research suggests that people want to reduce their own negative emotions even when simply learning about a transgression 
of an ingroup member (i.e., a group-based emotion), let alone a transgression they committed themselves (Porat et al., 2020). Such evidence is consistent with an assumption of "racial comfort" that White people may hold (DiAngelo, 2018), whereby White individuals will commonly prioritize their own comfort when considering racism (e.g., their own biased behaviors or their involvement in racist systems; Cabrera et al., 2016). Seeking comfort may often take the form of trying to reduce the negative emotions that characterize the fragility emotional response, but can also take the form of increasing positive emotion (e.g., hope, in-group pride).

We also note that someone does not need to be currently experiencing an emotion for emotion regulation to occur. Regulation can be initiated in anticipation of an emotion, to avoid the emotion before it even starts. Indeed, this anticipatory regulation - which can be very effective may be one of the principal reasons that certain emotions, like group-based guilt (feeling badly about something one's group did; e.g., a White person feeling guilty about their relative advantage as a function of their racial group) are relatively uncommonly experienced (Wohl et al., 2006). Whether in response to or in anticipation of an emotion, upon deciding to prioritize comfort, the individual will then select a strategy they believe will help them achieve this desired state.

\section{Selecting Strategies}

To seek comfort and manage negative emotions in daily life, people have many different strategies to choose from. To map out these different options, it is again useful to consider the elements of emotion generation: each element - the situation, the attention paid to it, how it is appraised, and the ultimate response - provides a different target for different emotion regulation strategies (Gross, 2015). Specifically, people can modify the situation, redirect their attention, reappraise the situation, or modulate their behavioral responses. This systematic framework can organize the many types of emotion regulation that prior theorizing and limited research have 
considered in the context of White fragility (DiAngelo, 2018; Langrehr et al., 2021; Liebow \& Glazer, 2019). See Figure 1 for a visual representation of how different families of regulation strategies can address each stage of the generation of a fragility emotional response.

\section{Implementing Strategies}

Upon selecting a strategy (or strategies), the individual will then implement their approach by using a specific tactic (or tactics) to engage in a particular instance of emotion regulation. We specifically propose that White fragility is typically characterized by people choosing tactics that involve disengagement (i.e., avoiding or turning away from the situation or one's emotions, etc.). There are multiple reasons for this type of regulatory response. For example, most White people have been socialized to avoid talking or thinking about race (Loyd \& Gaither, 2018) and so it may be a natural inclination to manage emotions around race using a similar avoidance-based approach (Howell et al., 2013). In addition, White fragility emotional responses are often acutely distressing and research from outside a racial context suggests that people often choose disengagement tactics to gain quick relief from high-intensity stressors (Sheppes et al, 2011).

These disengagement tactics can be implemented at each step of the process (see examples in Figure 1): In striving to modify the situation itself, people may exit the situation or avoid future similar situations. Indeed, prior research confirms that White participants often avoid talking about race and avoid interracial interactions because they expect them to be unpleasant (Apfelbaum et al., 2008; Plant, 2004). In striving to redirect their attention, people may tune out or redirect attention away from the situation (e.g., distraction). For example, colorblindness - whereby White individuals deny seeing color or race in themselves or others (Lewis, 2004; Phillips \& Lowery, 2018) - is a common and potent example of avoiding attention to racial cues. In striving to reappraise, we propose people may be particularly likely to address their original appraisal for whether the situation 
is incongruent with their goals by reframing the nature of the situation itself. That is, reappraisal can be used to reframe the situation so it is less incongruent with their goals - for example, by minimizing its severity (e.g., "it's not that bad") or denying personal responsibility (e.g., "it's not my fault") (Knowles et al., 2014). It is important to note that many of these strategies can be used preemptively, to avoid the emotional experience before it begins or takes hold. Finally, in striving to modify their behavioral responses, people may hide the outward expression of their emotions (i.e., expressive suppression), stonewall, or otherwise shut down (Crandall \& Eshleman, 2003).

Prior research conducted outside of race-related contexts indicates that disengagement tactics are relatively successful at helping reduce negative emotion in the short-run by allowing distressing information to be circumvented (Sheppes et al., 2011). White people may even be particularly successful at using such tactics. For example, due to their relatively privileged status, White people may be especially able to successfully avoid situations that would force them to uncomfortably confront their own privilege (e.g., maintaining relatively homogenous social networks that limit exposure to Black community members; Liebow \& Glazer, 2019; Phillips \& Lowery, 2018).

As people monitor the progress of their implemented strategy, they often learn that it helped them feel better (because these strategies are often successful in the short term). Indeed, although White fragility is often discussed as involving largely failed emotion regulation, we propose that fragility regulatory responses are reinforced because they are often successful in helping the White person feel better in the short term. These strategies, however, also deprive people of valuable sources of external feedback: Due to their disengaged nature, such strategies limit the White person's opportunity to learn about the consequences of their response, outside of their subjective experience. Without learning about the downsides of their response - and given the personal benefits of the response - it is likely they will continue using such strategies in the future. 
We have focused here on what prior literature and theory suggests are the modal forms of emotion regulation employed during White fragility: striving to reduce negative emotions through disengagement-focused tactics. However, it is important to note that atypical cases may nonetheless count as instances of White fragility. For example, someone can strive to enhance their negative emotions (e.g., increasing their sadness about being perceived as racist to convey their good intentions). Or someone can strive to reduce negative emotions through engagement-focused tactics that are anti-social or otherwise problematic (e.g., upon being angered by feedback that one's recent comment was discriminatory, someone can modify the situation by bullying the feedback-giver, getting them to back down and making it less likely they will speak up in the future).

\section{Interim Summary}

Here, we have emphasized that White fragility typically consists of patterns of emotional responses and/or patterns of disengagement-focused emotion regulation that unfold in response to situations in which a White person's racial identity is salient and a core goal to be 'good' is jeopardized. Altogether, we propose White fragility is most commonly manifested in four ways: (a) Someone may have the emotional response and successfully alleviate it using disengaged forms of emotion regulation; (b) Someone may avoid the emotional response by preemptively using disengaged forms of emotion regulation, circumventing the emotional response; (c) Someone may have the emotional response and try unsuccessfully to alleviate it using emotion regulation; and (d) Someone may have the emotional response and not try to regulate it. Given these various instantiations, some moments of White fragility can involve intense negative emotions, while others may not; some moments of White fragility can involve successful emotion regulation, while others may not. Given the numerous potential elicitors of these diverse types of fragility responses, we suggest that fragility responses are likely common and consequential in many people's daily lives. 


\section{The Consequences of White Fragility Responses}

We propose that White fragility emotions and emotion regulation efforts have broad consequences. Specifically, a White person's fragility response may be associated with personal costs (e.g., increased anxiety), interpersonal costs (e.g., decreased perspective taking), as well as societal costs (e.g., decreased engagement in social action). In our discussion of the consequences of a White person's fragility response, we draw on evidence from research in other race-related contexts including work on intergroup emotions and relations, interracial interactions, racial ideology, and solidarity-based collective action. Given that these bodies of work discuss emotions that are typically involved in the White fragility response (e.g., anger and anxiety experienced in a race-related contexts), it is useful to draw on this research to provide indirect evidence of the outcomes associated with White fragility responses.

\section{Consequences of the Emotional Response}

White fragility emotional reactions often involve negative emotions such as anger, anxiety, guilt, and sadness (DiAngelo, 2018). These emotional responses can have a variety of consequences.

\section{Personal Consequences}

Research conducted in the domain of interracial interactions has found that experiencing and expressing negative emotions can be cognitively and physiologically taxing (e.g., Trawalter et al., 2009). For instance, negative emotions, including feelings of anxiety, are often linked to physiologically costly responses such as increases in cortisol levels and inefficient cardiovascular responses (Mendes et al., 2002; Trawalter et al., 2012). Specifically, in samples of predominantly White individuals, interactions with a Black partner were associated with inefficient cardiovascular responses (e.g., Mendes et al., 2002). This indirect evidence suggests that the negative emotions that tend to characterize White fragility responses are associated with adverse personal outcomes. 


\section{Interpersonal Consequences}

Emotional reactions involved in the White fragility response can also negatively impact interpersonal outcomes. For example, in interracial interactions, Black individuals can "catch" stress from anxious White interaction partners (West et al., 2017), which can damage the longer-term health and well-being of these Black individuals (Levy et al., 2016). Or, in the classroom, White students who are taught about White privilege tend to evaluate their teachers more negatively, likely rooted in feelings of discomfort and distress the students experienced when asked to reflect on their ingroup's unearned benefits (Boatright-Horowitz \& Soeung, 2009). Given that course evaluations are weighted heavily when making promotion decisions (Murray et al., 2020), a negative evaluation can adversely impact an instructor's career or livelihood, demonstrating the stark longer-term interpersonal drawbacks of White fragility.

\section{Societal Consequences}

Emotional reactions involved in the White fragility response can also be associated with societal costs. A fragility response characterized by anger toward the outgroup would likely promote aggression and confrontation (Mackie et al., 2000). Likewise, a fragility response characterized by feelings of sadness and tearful denials of personal responsibility of racism in racism-centered conversations can effectively sideline further conversation about racial inequality (e.g., "White women's tears"; Accapadi, 2007). Given that racism-centered conversations play an important role in increasing racism awareness and fostering support for affirmative action (Case, 2007), emotional reactions involved in the White fragility response can stifle discussions about topics such as racial inequality thereby decreasing the motivation to change the status quo.

Emotions involved in the White fragility response are largely associated with personal, interpersonal, and societal costs. However, certain self-focused emotions such as guilt or self- 
focused anger could also be beneficial in coordinating efforts to solve complex social problems (e.g., racial inequality; e.g., Swim \& Miller, 1999). For example, when White participants assessed statements about racial inequality that were framed in terms of White privilege (relative to Black disadvantage), they experienced more group-based guilt (Powell et al., 2005), and when advantaged group members reflected on their unfair advantages over a disadvantaged group, they experienced more anger about the ingroup advantage (i.e., self-focused anger; Leach et al., 2006). These feelings of guilt and self-focused anger predicted willingness to engage in collective action to redress the disadvantages faced by a structurally disadvantaged outgroup (e.g., Leach et al., 2006).

Although some negative emotions that characterize White fragility may be associated with beneficial collective action (e.g., collective guilt; Swim \& Miller, 1999), these emotional reactions do not always promote useful behaviors. If feelings of guilt and self-focused anger are intense, for instance, the individual could be so absorbed by their negative emotions that they do not take useful action, or they may even punish the source of their negative emotions (Boatright-Horowitz \& Soeung, 2009). Even in cases where White fragility emotional responses may promote beneficial collective behavior, people might be so motivated to avoid that guilt that they rarely get the chance to enact those benefits (Rotella \& Richeson, 2013) - an idea to which we turn to next.

\section{Consequences of the Regulatory Response}

We have proposed that White fragility is also characterized by using disengagement forms of emotion regulation (e.g., avoidance, minimizing), which can be effective in reducing the White fragility emotional responses. The use of these emotion regulation strategies, however, can still come with personal, interpersonal, and societal costs.

\section{Personal Consequences}


Avoiding anxiety-eliciting situations can be effective strategies for reducing negative emotions in the short-term (Gross, 2015), but such strategies can also be associated with long-term personal costs for White individuals. White individuals, for instance, may avoid intergroup interactions to manage their anxiety (Plant, 2004), but such intergroup contact plays an important role in reducing intergroup anxiety (Pettigrew \& Tropp, 2006). Thus, avoiding interracial interactions may reduce intergroup anxiety in the short-term, but continued avoidance of these interactions may maintain or even increase intergroup anxiety over time.

If White individuals are not able to avoid an interracial interaction, they may engage in other forms of disengagement-focused emotion regulation within these interactions. For example, White individuals might effortfully try to suppress stereotypical thoughts and/or anxious expressions and behaviors, especially when having race-related relative to race-neutral conversations (Richeson \& Trawalter, 2005). In turn, White participants who appeared to be suppressing their behaviors in an interracial interaction performed more poorly on a measure of response inhibition (i.e., Stroop colornaming task; Richeson \& Shelton, 2003), suggesting their cognitive functioning was compromised. Taken together, this research suggests that in contexts that evoke White fragility, the use of disengagement strategies to manage negative emotional reactions can exacerbate these negative emotions in the long-run and adversely impact cognitive functioning which could jeopardize the use of less problematic emotion regulation strategies (e.g., Ford \& Troy, 2019).

\section{Interpersonal Consequences}

In contexts where racial identity is made salient, disengagement-focused emotion regulation strategies can have a negative impact on interpersonal outcomes. In interracial interactions, White people often engage in strategic colorblindness where they avoid talking about race (Apfelbaum et al., 2008) to appear non-prejudiced and manage the discomfort associated with race-related 
discussions (Apfelbaum et al., 2008; Mekawi et al., 2020), but these efforts often backfire. For example, in a series of studies (Apfelbaum et al., 2008; Norton et al., 2006), White participants completed a photo identification task with either a Black or White partner, trying to get their partner to identify a target photograph using as few yes/no questions as possible. Although photos varied on several dimensions including race and gender, White participants were less likely to mention race (i.e., engaged in strategic colorblindness) when paired with a Black relative to a White partner. When White individuals engaged in strategic colorblindness, they displayed behaviorally avoidant non-verbal behaviors (Apfelbaum et al., 2008; Norton et al., 2006), and as a result, Black observers rated them as less friendly (Apfelbaum et al., 2008).

White people may also minimize or deny the prevalence of racism to manage feelings of collective guilt. Avoiding feelings of guilt, however, is related to reduced intergroup empathy and less perspective taking (Mekawi et al., 2017, 2020). Reduced intergroup empathy and perspective taking can, in turn, hinder the development of cross-race friendships (Spanierman et al., 2009).

White people may also manage their own emotions by trying to change the emotions of their Black interaction partners in racism-centered conversations. Theorists have described this scenario as a form of affective injustice: situations where people of color are called upon to regulate their feelings of anger triggered by perceived injustices. In addition to the original injustice (e.g., being the target of discrimination), the expectation that people of color will reduce their anger represents an additional affective injustice (Archer \& Mills, 2019; Srinivasan, 2018). Such affective injustices likely benefit White individuals: when people of color regulate their own anger, it might prevent their White interaction partners from feeling uncomfortable. However, engaging in such forms of extrinsic emotion regulation shifts attention away from the racial injustice and prioritizes the White individual and alleviating their discomfort (Bryant-Davis, 2005). This process invalidates an 
interaction partner's point of view and prevents further discussion of racial inequality. Overall, disengagement-focused emotion regulation strategies are associated with personal benefits (e.g., reduced negative affect) but even greater interpersonal costs (e.g., reduced intergroup empathy).

\section{Societal Consequences}

Disengagement-focused forms of emotion regulation often serve to deny the underlying problem of racism or distance oneself from one's role in that problem (e.g., Mekawi et al., 2020), which can bring broader societal consequences. Specifically, these forms of emotion regulation are particularly likely to impair White people's motivation to address anti-Black racism and White privilege (cf. Knowles et al., 2014; Phillips \& Lowery, 2018). For example, avoiding interracial contact may reduce the likelihood of taking collective action in concert with members of disadvantaged groups (e.g., Craig et al., 2020). Additionally, undergraduates who reported denying racism and minimizing the extent of racism were less interested in campus diversity activities and less supportive of affirmative action (Mekawi et al., 2020). Overall, engaging in disengagementforms of emotion regulation that reduce or sideline conversations about racial inequality can negatively impact collective outcomes over the long-term.

These forms of emotion regulation can also be undertaken on behalf of other people. As one particularly potent example of this, a number of U.S. legislators in 2021 specifically sought to prevent the emotional "discomfort, guilt, anguish or another form of psychological distress" associated with confronting racism by introducing laws limiting how teachers can talk about race in the classroom (Foster et al., 2021). This is a powerful example of White people enacting (and institutionalizing) disengagement strategies that prioritize the emotional comfort of White people over opportunities to critically reflect upon and change the status quo.

\section{Interim Summary}


White fragility emotional reactions and efforts to regulate these emotional reactions are associated with personal, interpersonal, and societal consequences, many of which are harmful. Although there is overlap in the consequences associated with White fragility emotional responses (e.g., experiencing negative emotions) and with White fragility regulatory responses (e.g., avoiding these negative emotions), they do not always lead to the same outcomes. For example, although some White fragility emotional responses could even be interpersonally or societally beneficial (e.g., guilt promoting reparative behaviors), these benefits are often negated by White fragility emotion regulation (e.g., because guilt feels unpleasant, people often use disengagement-focused emotion regulation to avoid it, therefore negating its possible benefits). This pattern highlights the unique consequences of White fragility emotions and White fragility emotion regulation, which both merit future empirical investigation. Overall, given the short-term and long-term consequences of the emotional and regulatory responses that characterize White fragility, it is important to identify ways forward that avoid these consequences.

\section{Ways Forward}

We have argued that emotion and emotion regulation theory provide important insights into White fragility responses and their consequences. Although we highlighted many existing lines of work that begin to speak to these issues, much of this research is relatively indirect and there remain many avenues for future work to examine the numerous elicitors and contexts of fragility, as well as the numerous emotional responses and regulation strategies that characterize fragility. For example, we often illustrated White fragility in the context of Black people (due to the historical significance of these groups and because empirical research on race has often focused on these groups), but we note that White fragility should theoretically be relevant to all people of color who face oppression. We hope the conceptual framework provided here serves to both structure and inspire future work. 
Our analysis highlights the utility of conceiving of a White fragility response as a state evoked by particular underlying processes (e.g., processes involved in generating emotional responses and emotion regulation efforts), rather than as a trait (i.e., a characteristic of particular people). Although certain traits may increase the likelihood that someone may have more frequent and/or intense fragility responses, we have argued that the numerous possible elicitors of fragility make fragility responses a possibility for nearly all White people. This process-oriented perspective, in turn, suggests points of intervention that can help in developing practical tools to overcome White fragility responses. Here, we argue that the broader emotion regulation literature can again be leveraged to identify promising approaches for dealing with White fragility responses that do not undermine racialized community members or systemic change.

Given that systemic change across many domains in American life is necessary (e.g., addressing disparities in the systems for criminal justice, education, health care, etc.), some may wonder whether focusing on individuals' emotion regulation is a productive path forward. We propose this is a useful entry point because systems do not often change themselves - people need to change them, through collective action and/or the direct action of people in power. Gaining traction within individuals should be an important precursor to many forms of sustainable systemic change and because White fragility responses represent a barrier to that traction, reducing those responses should be useful. Below, we describe several promising approaches, noting that although they are theoretically-justified and supported by preliminary findings, these ideas are largely speculative and additional future research is needed to verify their efficacy before they are implemented broadly.

\section{Acceptance of Discomfort}

One potential step forward is for White people to build acceptance for their discomfort. It is uncomfortable to consider one's racism and involvement in racist systems, and we have argued that 
White people will often prioritize their comfort during such moments, using strategies characterized by disengagement and avoidance, even though these strategies are likely to perpetuate longer-term harm. One viable way to avoid the harm these strategies can cause within this context is to question the premise that one needs to get rid of their discomfort in the first place (e.g., to 'problematize' the notion of comfort in this context; cf. Frawley, 2018). Rather than trying to avoid one's emotions, one can accept one's emotions. Notably, we do not suggest that emotional acceptance is not an end in itself, but rather, is a first step that can allow for more productive subsequent responses.

Emotional acceptance involves actively acknowledging and bringing awareness to negative emotions without judging or attempting to avoid those emotions (Segal et al., 2004). In doing so, negative emotional episodes are allowed to run their natural course and then dissipate, even in highly stressful situations (Ford et al., 2018; Shallcross et al., 2010). Emotional acceptance can also help avoid negative meta-emotions, or emotional reactions to one's own emotions (e.g., feeling angry about feeling guilty), which can be particularly damaging. Emotional acceptance can also be applied extrinsically, as White people accept the negative emotions of Black community members experiencing racism and therefore avoid the affective injustice of expecting or encouraging Black people to manage these emotions (cf. Archer \& Mills, 2019; Srinivasan, 2018). Moreover, acceptance of discomfort might allow for more productive emotions to follow, such as gratitude for the opportunity to grow, or curiosity about oneself or others (DiAngelo, 2018).

Crucially, emotional acceptance is also thought to promote self-awareness by allowing people to acknowledge emotions as they unfold, as well as the underlying reasons for those emotions (Hayes \& Wilson, 2003). For example, a more accepting approach towards one's emotions may help someone stay attuned to and tolerate their unpleasant emotions (e.g., guilt) at a moderate level, which could be ideal for promoting effective reparative action (e.g., apologizing; cf. Liebow 
\& Glazer, 2019). Indeed, a moderate amount of discomfort can serve as an important catalyst for action (Carter et al., 2020; Ford \& Feinberg, 2020). However, some emotions may still impair effective reparative action (e.g., distractingly intense emotions) or lead to further confrontation (e.g., out-group anger), and would benefit from more direct management, which we turn to next.

\section{Enacting Less Problematic Emotion Regulation}

Given that many White fragility emotional responses may need to be regulated to reduce the interpersonal and societal costs of those emotions, it is crucial to identify regulation strategies that are unlikely to come with their own costs. One way to avoid the costs of using disengagement-based strategies - the characteristic regulatory choices of White Fragility - is to use alternative strategies that are centered on engagement (cf. Sheppes et al., 2011): managing emotions using strategies that allow the individual to stay connected to the situation, connected to what it means, and connected to the people who would benefit from support ${ }^{2}$. To organize the conceptual space of these strategies, we again consider the different elements of emotion generation, given that each element - the situation, the attention paid to it, how it is appraised, and the ultimate response - provides a different target for alternative, engagement-focused emotion regulation strategies, which we describe below.

When considering how to address the situation itself, rather than avoiding situations that might require one to think about one's race, racial privilege, or potential biased behavior, White people can seek out these situations as beneficial opportunities. For example, in a brief intervention, researchers highlighted for participants the fact that anxiety often spurs people to avoid interracial interactions and that choosing to instead approach such interactions may be more beneficial in

\footnotetext{
${ }^{2}$ We also note two important caveats of engagement. First, there can be drawbacks to excessive engagement from White individuals, such as when they rely too heavily on Black community members for information or feedback and therefore become a burden (cf. DiAngelo, 2021), even leading to burnout among Black activists (Gorski \& Erakat; 2019). Second, engagement can be used in the service of White fragility (highlighted above in the section on 'White Fragility: The Regulatory Response'). For example, someone receives feedback from a coworker about biased behavior and to cope with the situation they bully the coworker into backing down, also making it less likely they will speak up in the future).
} 
reducing longer-term anxiety (Schultz et al., 2015). In turn, participants in this intervention (vs. controls) were more likely to choose to interact with a Black partner over a White partner and showed more positive nonverbal engagement during the interracial interaction. By gaining awareness of the emotion-regulatory role of avoidance, participants counteracted their natural tendency to disengage from possibly distressing situations and were instead able to have a more positive interaction. Although such interactions may be less frequent for White people who live in racially homogenous environments (which is common; Rothstein, 2017), White people can still seek out opportunities to productively engage with - and not avoid - race and racial privilege (e.g., in the media and stories they consume, the businesses they support, the policies they vote for).

When considering how to change their attention to the situation, rather than paying less attention (e.g., distracting oneself, tuning out), White people can bring more awareness to the moment. It is plausible that many of the emotion regulation strategies people use during White fragility could be activated outside of conscious awareness, which means that increasing awareness is a crucial early step. For example, raising awareness of the racism that Black individuals face as they navigate daily American life may be a crucial precursor to experiencing empathic concern (i.e., compassion for another's welfare) which can promote prosocial behavior (cf. Batson et al., 2007; Todd et al., 2012). However, whether this attention is directed internally (e.g., awareness of one's distress) or externally (e.g., awareness of another's distress), this attention could exacerbate one's emotional response and prompt disengagement strategies to reduce that distress unless the attention is paired with a change in mindset - how one appraises the context - which we turn to next.

When considering how to change their appraisal(s), rather than relying on disengagementfocused tactics that reframe the situation so it is less incongruent with their goals (e.g., minimizing the situation's severity or denying personal responsibility), White people can use engagement- 
focused reappraisal tactics that involve turning toward the situation and considering other valued goals (McRae et al., 2012; Murphy et al., 2011). For example, the situation could be reframed as a valuable opportunity to grow, learn, connect with others, or put another's needs above one's own (Park, 2010). Reframing the situation as an opportunity for growth and learning can help with responding more adaptively to negative feedback about the self or one's group which could promote better outcomes when similar situations arise in the future (Yeager \& Dweck, 2012). Reframing the situation by doing one's best to consider it from the perspective of Black community members could help override the powerful ingroup-outgroup representations White people often hold (cf. Fraser et al., 2020; Gutsell \& Inzlicht, 2010) and promote feelings of sympathy or moral outrage that can enhance support for anti-racism efforts (cf. Hoffman, 1990). Engagement-focused reappraisals may even deter disengagement-focused reappraisals: For example, reconsidering a race-centered situation as an opportunity to demonstrate personal strengths (i.e., a self-affirmation manipulation) disrupted advantaged people's tendency to defensively rationalize their privilege - a key path through which White people maintain dominance (Phillips \& Lowery, 2018). Overall, there are many ways in which White people can change how they're thinking about a situation to mitigate negative emotions without downstream costs to Black community members.

When considering how to change their behavioral responses of emotion, White people can again shift away from disengagement (e.g., stonewalling). For example, engaging in paced deep breathing can directly reduce physiological activation (Pal et al., 2004), which can calm the body in service of also calming one's emotional response. Such approaches may be especially useful when paired with other engagement strategies mentioned above that target the root of the emotional experience (e.g., changing one's appraisals). 
In sum, we suggest that an emotion regulation perspective can be used to both elucidate the problems inherent in White fragility and point towards more effective paths forward. Although it is likely that some people are not motivated to reduce White fragility responses (e.g., those who do not believe such a response is problematic), change must begin somewhere. It may be reasonable to begin with those who are already motivated to make change (especially given that well-intentioned White people can still exhibit harmful race-related behaviors; DiAngelo, 2021). Changes within this group can then result in broader shifts as they bring their approach to others, creating communitylevel shifts in norms or behaviors over time and increasing the fertility of the ground for subsequent wider-scale intervention. We highlight that emotion regulation is not the endpoint, but rather is a tool that can address White fragility in vivo and help avoid the damage White fragility can have on racial justice. To achieve sustainable change, an emotion-regulation perspective may be usefully paired with other tools that combat racism such as prejudice-reduction interventions, where White fragility is likely to arise. Indeed, a recent meta-analysis indicates that such interventions are often short-lived and have modest effect sizes (Paluck et al., 2020). As such, an emotion-regulation perspective could provide practical insights into a more effective management of White fragility when needed most, enhancing interventions that target structures in deep need of change.

\section{Beyond White Fragility: A Broader Theoretical Lens?}

In this article, we have focused on White fragility responses. However, it is important to acknowledge that we are all embedded in a complex multi-dimensional social space, where each person is a part of multiple groups or spectra - including but not limited to race - and each is associated with their own power differentials (e.g., gender, sexual orientation, social class, religion). Although scholarly pursuits can often benefit from considering one dimension at a time, as we have done in this article, this does not reflect the reality of daily life. Day to day, these dimensions co- 
occur and intersect, often becoming more versus less salient due to relevant contextual factors. Beyond White fragility, we propose that people at the more powerful ends of any sociallyconstructed dimension could exhibit a fragility response. A high power fragility framework allows us to consider fragility responses based on multiple and possibly interacting high-power positions.

As an example of an additional power dimension on which fragility can be experienced and intersect with White fragility - let us consider gender. A man could experience a fragility response upon being called out for a sexist behavior: he experiences an emotional response (e.g., anger, guilt) which he tries to regulate (e.g., denying personal responsibility, "I didn't mean it that way"). This fragility response, in turn, comes with costs as the emotion and/or its regulation negatively affects both his female interaction partner and others who witness the exchange. These costs will be even greater when additional power differentials are layered in, as when a White man has a fragility response to being called out for sexist and/or racist behavior towards a Black woman. Given the unique, historically-rooted power structures that support White people, and particularly White men, a White man's emotional response and/or regulation of that response have particularly powerful implications for immediate and longer-term wellness of the people he interacts with.

An intersectional framework is essential for acknowledging the layers of oppression that can come from multiple marginalized identities (Lorde, 2020) and exploring how people can experience fragility based on multiple privileged identities. This broader 'high-power' fragility framework, in turn, can help unpack the role of fragility - both the emotional response and its regulation - in maintaining various intersecting systemic inequalities. By understanding this role, psychological science can play a vital role in dismantling these inequalities. 


\section{References}

Accapadi, M. M. (2007). When White women cry: How White women's tears oppress women of color. College Student Affairs Journal, 26, 208-215.

Apfelbaum, E. P., Sommers, S. R., \& Norton, M. I. (2008). Seeing race and seeming racist? Evaluating strategic colorblindness in social interaction. Journal of Personality and Social Psychology, 95, 918.

Archer, A., \& Mills, G. (2019). Anger, affective injustice, and emotion regulation. Philosophical Topics, 47, 75-94.

Bandura, A. (2002). Selective moral disengagement in the exercise of moral agency. Journal of Moral Education, 31, 101-119.

Barrett, L. F. (2012). Emotions are real. Emotion, 12, 413.

Batson, C. D., Eklund, J. H., Chermok, V. L., Hoyt, J. L., \& Ortiz, B. G. (2007). An additional antecedent of empathic concern: valuing the welfare of the person in need. Journal of personality and social psychology, 93(1), 65.

Bergsieker, H., Shelton, J. N., \& Richeson, J. A. (2010). To be liked versus respected: Divergent goals in interracial interactions. Journal of Personality and Social Psychology, 99, 248.

Boatright-Horowitz, S. L., Marraccini, M., \& Harps-Logan, Y. (2012). Teaching antiracism: College students' emotional and cognitive reactions to learning about white privilege. Journal of Black Studies, 43, 893-911.

Boatright-Horowitz, S. L., \& Soeung, S. (2009). Teaching White privilege to White students can mean saying good-bye to positive student evaluations. American Psychologist, 64, 574-75.

Boykin, C. M., Brown, N. D., Carter, J. T., Dukes, K., Green, D. J., Harrison, T., Hebl, M., McCleary-Gaddy, A., Membere, A., McJunkins, C. A., \& others. (2020). Anti-racist actions 
and accountability: Not more empty promises. Equality, Diversity and Inclusion: An International Journal.

Branscombe, N. R., Ellemers, N., Spears, R., Doosje, B., \& others. (1999). The context and content of social identity threat. Social Identity: Context, Commitment, Content, 35-58.

Bryant-Davis, T. (2005). Thriving in the Wake of Trauma: A Multicultural Guide. Praeger.

Cabrera, N., Watson, J. \& Franklin, J. D. (2016). Racial arrested development: A critical whiteness analysis of the campus ecology. Journal of College Student Development, 57, 119-134.

Carter, E. R., Onyeador, I. N., \& Lewis Jr, N. A. (2020). Developing \& delivering effective anti-bias training: Challenges \& recommendations. Behavioral Science \& Policy, 6, 57-70.

Case, K. A. (2007). Raising White privilege awareness and reducing racial prejudice: Assessing diversity course effectiveness. Teaching of Psychology, 34, 231-235.

Craig, M. A., Badaan, V., \& Brown, R. M. (2020). Acting for whom, against what? Group membership and multiple paths to engagement in social change. Current Opinion in Psychology, 35, 41-48.

Crandall, C. S., \& Eshleman, A. (2003). A justification-suppression model of the expression and experience of prejudice. Psychological Bulletin, 129, 414.

DiAngelo, R. (2011). White fragility. International Journal of Critical Pedagogy, 3, 54-70.

DiAngelo, R. (2018). White fragility: Why it's so hard for white people to talk about racism. Beacon Press.

DiAngelo, R. (2021). Nice Racism: How Progressive White People Perpetuate Racial Harm. Beacon Press.

Ford, B. Q., \& Feinberg, M. (2020). Coping with politics: The benefits and costs of emotion regulation. Current Opinion in Behavioral Sciences, 34, 123-128. 
Ford, B. Q., Lam, P., John, O. P., \& Mauss, I. B. (2018). The psychological health benefits of accepting negative emotions and thoughts: Laboratory, diary, and longitudinal evidence. Journal of Personality and Social Psychology, 115, 1075.

Ford, B. Q., \& Tamir, M. (2014). Preferring familiar emotions: As you want (and like) it? Cognition and Emotion, 28, 311-324.

Ford, B. Q., \& Troy, A. S. (2019). Reappraisal reconsidered: A closer look at the costs of an acclaimed emotion-regulation strategy. Current Directions in Psychological Science, 28, 195-203.

Foster, K., French, D., Stanley, J., \& Williams, T. (2021, July 5). We Disagree on a Lot of Things. Except the Danger of Anti-Critical Race Theory Laws. New York Times.

Frantz, C. M., Cuddy, A. J., Burnett, M., Ray, H., \& Hart, A. (2004). A threat in the computer: The race implicit association test as a stereotype threat experience. Personality and Social Psychology Bulletin, 30, 1611-1624.

Fraser, A. M., Hampton, R. S., Spinrad, T. L., Varnum, M., Blais, C., Eisenberg, N., ... \& Xiao, S. X. (2020). Children's mu suppression is sensitive to witnessing others' social victimization. Social Neuroscience, 15, 348-354.

Frawley, A. (2018). 'Unhappy News': Process, rhetoric, and context in the making of the happiness problem. Sociological Research Online, 23(1), 43-66.

Gillborn, D. (2005). Education policy as an act of white supremacy: Whiteness, critical race theory and education reform. Journal of education policy, 20(4), 485-505.

Goldenberg, A., Halperin, E., van Zomeren, M., \& Gross, J. J. (2016). The process model of groupbased emotion: Integrating intergroup emotion and emotion regulation perspectives. Personality and Social Psychology Review, 20, 118-141. 
Gorski, P. C., \& Erakat, N. (2019). Racism, whiteness, and burnout in antiracism movements: How white racial justice activists elevate burnout in racial justice activists of color in the United States. Ethnicities, 19(5), 784-808.

Gross, J. J. (2015). Emotion regulation: Current status and future prospects. Psychological Inquiry, $26,1-26$.

Gutsell, J. N., \& Inzlicht, M. (2010). Empathy constrained: Prejudice predicts reduced mental simulation of actions during observation of outgroups. Journal of Experimental Social Psychology, 46, 841-845.

Hayes, S. C., \& Wilson, K. G. (2003). Mindfulness: Method and process. Clinical Psychology: Science and Practice, 10, 161-165.

Helms, J. E. (1997). Toward a model of White racial identity development. College Student Development and Academic Life: Psychological, Intellectual, Social \& Moral Issues, 49-66.

Hoffman, M. L. (1990). Empathy and justice motivation. Motivation and emotion, 14(2), 151-172.

Howell, J. L., Collisson, B., Crysel, L., Garrido, C. O., Newell, S. M., Cottrell, C. A., Smith, C. T., \& Shepperd, J. A. (2013). Managing the threat of impending implicit attitude feedback. Social Psychological and Personality Science, 4, 714-720.

Jost, J. T., \& Hunyady, O. (2005). Antecedents and consequences of system-justifying ideologies. Current directions in psychological science, 14, 260-265.

Knowles, E. D., Lowery, B. S., Chow, R. M., \& Unzueta, M. M. (2014). Deny, distance, or dismantle? How white Americans manage a privileged identity. Perspectives on Psychological Science, 9, 594-609.

Kraus, M., Onyeador, I., Daumeyer, N., Rucker, J., \& Richeson, J. (2019). The misperception of racial economic inequality. Perspectives on Psychological Science, 14, 899-921. 
Langrehr, K. J., Watson, L. B., Keramidas, A., \& Middleton, S. (2021). The development and initial validation of the White Fragility Scale. Journal of Counseling Psychology.

Lazarus, R. S. (1991). Emotion and adaptation. Oxford University Press.

Leach, C., Iyer, A., \& Pedersen, A. (2006). Anger and guilt about ingroup advantage explains the willingness for political action. Personality and Social Psychology Bulletin, 32, 1232-45.

Levy, D. J., Heissel, J. A., Richeson, J. A., \& Adam, E. K. (2016). Psychological and biological responses to race-based social stress as pathways to disparities in educational outcomes. American Psychologist, 71, 455-473.

Lewis, A. E. (2004). "What group?" Studying whites and whiteness in the era of "color-blindness. Sociological Theory, 22, 623-646.

Liebow, N., \& Glazer, T. (2019). White tears: Emotion regulation and white fragility. Inquiry. Lorde, A. (2020). Sister outsider: Essays and speeches. Penguin Classics.

Loyd, A. B., \& Gaither, S. E. (2018). Racial/ethnic socialization for White youth: What we know and future directions. Journal of Applied Developmental Psychology, 59, 54-64.

Mackie, D. M., Devos, T., \& Smith, E. R. (2000). Intergroup emotions: Explaining offensive action tendencies in an intergroup context. Journal of Personality and Social Psychology, 79, 602616.

McIntosh, P. (2020). White privilege and male privilege: A personal account of coming to see correspondences through work. Privilege and prejudice: Twenty years with the invisible knapsack, 7.

McRae, K., Ciesielski, B., \& Gross, J. J. (2012). Unpacking cognitive reappraisal: goals, tactics, and outcomes. Emotion, 12, 250.

Mekawi, Y., Bresin, K., \& Hunter, C. D. (2017). Who is more likely to "not see race"? Individual 
differences in racial colorblindness. Race and Social Problems, 9, 207-217.

Mekawi, Y., Todd, N. R., Yi, J., \& Blevins, E. J. (2020). Distinguishing “I don’t see color” from "Racism is a thing of the past": Psychological correlates of avoiding race and denying racism. Journal of Counseling Psychology, 67, 288-302.

Mendes, W. B., Blascovich, J., Lickel, B., \& Hunter, S. (2002). Challenge and threat during social interactions with White and Black men. Personality and Social Psychology Bulletin, 28, 939-952.

Miyamoto, Y., Ma, X., \& Petermann, A. G. (2014). Cultural differences in hedonic emotion regulation after a negative event. Emotion, 14, 804.

Moors, A., Ellsworth, P. C., Scherer, K. R., \& Frijda, N. H. (2013). Appraisal theories of emotion: State of the art and future development. Emotion Review, 5, 119-124.

Murphy, M., Richeson, J. A., \& Molden, D. C. (2011). Leveraging motivational mindsets to foster positive interracial interactions. Social and Personality Psychology Compass, 5, 118-131.

Murray, D., Boothby, C., Zhao, H., Minik, V., Bérubé, N., Larivière, V., \& Sugimoto, C. R. (2020). Exploring the personal and professional factors associated with student evaluations of tenure-track faculty. PLOS ONE, 15, e0233515.

Nelson, J. K., Dunn, K. M., \& Paradies, Y. (2011). Bystander anti-racism: A review of the literature. Analyses of Social Issues and Public Policy, 11, 263-284.

Norton, M. I., Sommers, S. R., Apfelbaum, E. P., Pura, N., \& Ariely, D. (2006). Color blindness and interracial interaction: Playing the political correctness game. Psychological Science, 17, 949-953.

Pal, G. K., Velkumary, S., \& others. (2004). Effect of short-term practice of breathing exercises on autonomic functions in normal human volunteers. Indian Journal of Medical Research, 120, 
115.

Paluck, E. L., Porat, R., Clark, C. S., \& Green, D. P. (2020). Prejudice reduction: Progress and challenges. Annual Review of Psychology, 72.

Park, C. (2010). Making sense of the meaning literature: An integrative review of meaning making and its effects on adjustment to stressful life events. Psychological Bulletin, 136, 257.

Perry, S. P., Murphy, M. C., \& Dovidio, J. F. (2015). Modern prejudice: Subtle, but unconscious? The role of Bias Awareness in Whites' perceptions of personal and others' biases. Journal of Experimental Social Psychology, 61, 64-78.

Pettigrew, T. F., \& Tropp, L. R. (2006). A meta-analytic test of intergroup contact theory. Journal of Personality and Social Psychology, 90, 751-783.

Phillips, L. T., \& Lowery, B. S. (2018). Herd invisibility: The psychology of racial privilege. Current Directions in Psychological Science, 27, 156-162.

Plant, E. A. (2004). Responses to interracial interactions over time. Personality and Social Psychology Bulletin, 30(, 1458-1471.

Plant, E. A., \& Devine, P. G. (2003). The antecedents and implications of interracial anxiety. Personality and Social Psychology Bulletin, 29, 790-801.

Porat, R., Tamir, M., \& Halperin, E. (2020). Group-based emotion regulation: A motivated approach. Emotion, 20(1), 16.

Powell, A. A., Branscombe, N. R., \& Schmitt, M. T. (2005). Inequality as ingroup privilege or outgroup disadvantage: The impact of group focus on collective guilt and interracial attitudes. Personality and Social Psychology Bulletin, 31, 508-521.

Richeson, J. A., \& Shelton, J. N. (2003). When prejudice does not pay: effects of interracial contact on executive function. Psychological Science, 14(3), 287-290. 
Richeson, J. A., \& Trawalter, S. (2005). Why do interracial interactions impair executive function? A Resource Depletion Account. Journal of Personality \& Social Psychology, 88, 934-947.

Rotella, K. N., \& Richeson, J. A. (2013). Body of guilt: Using embodied cognition to mitigate backlash to reminders of personal \& ingroup wrongdoing. Journal of Experimental Social Psychology, 49, 643-650.

Rothstein, R. (2017). The color of law: A forgotten history of how our government segregated America. Liveright Publishing.

Schultz, J. R., Gaither, S. E., Urry, H. L., \& Maddox, K. B. (2015). Reframing anxiety to encourage interracial interactions. Translational Issues in Psychological Science, 1(4), 392.

Segal, Z. V., Teasdale, J. D., \& Williams, J. M. G. (2004). Mindfulness-Based Cognitive Therapy: Theoretical Rationale and Empirical Status.

Shallcross, A. J., Troy, A. S., Boland, M., \& Mauss, I. B. (2010). Let it be: Accepting negative emotional experiences predicts decreased negative affect and depressive symptoms. Behaviour Research and Therapy, 48, 921-929.

Sheppes, G., Scheibe, S., Suri, G., \& Gross, J.J. (2011). Emotion regulation choice. Psychological Science, 22, 1391-1396

Siemer, M., Mauss, I., \& Gross, J. J. (2007). Same situation--different emotions: how appraisals shape our emotions. Emotion, 592-600.

Smith, E. R., \& Mackie, D. M. (2008). Intergroup emotions. Handbook of Emotions, 3, 428-439.

Spanierman, L. B., Todd, N. R., \& Anderson, C. J. (2009). Psychosocial costs of racism to Whites: Understanding patterns among university students. Journal of Counseling Psychology, 56, 239-252.

Srinivasan, A. (2018). The aptness of anger. Journal of Political Philosophy, 26, 123-144. 
Srivastava, S. (2005). "You're calling me a racist?" The moral and emotional regulation of antiracism and feminism. Signs: Journal of Women in Culture and Society, 31, 29-62.

Swim, J. K., \& Miller, D. L. (1999). White guilt: Its antecedents and consequences for attitudes toward affirmative action. Personality and Social Psychology Bulletin, 25, 500-514.

Tamir, M. (2016). Why do people regulate their emotions? A taxonomy of motives in emotion regulation. Personality and Social Psychology Review, 20, 199-222.

Todd, A. R., Bodenhausen, G. V., \& Galinsky, A. D. (2012). Perspective taking combats the denial of intergroup discrimination. Journal of Experimental Social Psychology, 48, 738-745.

Trawalter, S., Adam, E. K., Chase-Lansdale, P. L., \& Richeson, J. A. (2012). Concerns about appearing prejudiced get under the skin: Stress responses to interracial contact in the moment and across time. Journal of Experimental Social Psychology, 48, 682-693.

Trawalter, S., Richeson, J., \& Shelton, J. (2009). Predicting behavior during interracial interactions: A stress and coping approach. Personality and Social Psychology Review, 13, 243-268.

Vitriol, J. A., \& Moskowitz, G. B. (2021). Reducing defensive responding to implicit bias feedback: On the role of perceived moral threat and efficacy to change. Journal of Experimental Social Psychology, 96, 104165.

West, T. V., Koslov, K., Page-Gould, E., Major, B., \& Mendes, W. B. (2017). Contagious anxiety: Anxious European Americans can transmit their physiological reactivity to African Americans. Psychological Science, 28, 1796-1806.

Wohl, M., Branscombe, N., \& Klar, Y. (2006). Collective guilt: Emotional reactions when one's group has done wrong or been wronged. European Review of Social Psychology, 17, 1-37.

Yeager, D. S., \& Dweck, C. S. (2012). Mindsets that promote resilience: When students believe that personal characteristics can be developed. Educational Psychologist, 47, 302-314. 